\title{
Research on Progress of Tribological Modification of Polyetheretherketone
}

\author{
Li Shu Long", Wang Yan Jun ${ }^{1, *}$, Qin Ke², Li Chao' \\ ${ }^{1}$ School of Mechanical Engineering, University of Jinan, Jinan, China \\ ${ }^{2}$ Shandong Machinery Industry Association, Jinan, China \\ Email address: \\ 1101701864@qq.com (Li Shu Long),me_wangyj@ujn.edu.cn (Wang Yan Jun), qinke227@sina.com (Qin Ke), \\ 1600359600@qq.com (Li Chao) \\ ${ }^{*}$ Corresponding author
}

\section{To cite this article:}

Li Shu Long, Wang Yan Jun, Qin Ke, Li Chao. Research on Progress of Tribological Modification of Polyetheretherketone. International Journal of Materials Science and Applications. Vol. 5, No. 2, 2016, pp. 102-107. doi: 10.11648/j.ijmsa.20160502.21

Received: April 9, 2016; Accepted: May 5, 2016; Published: May 9, 2016

\begin{abstract}
The characteristics and application of poly ether ether ketone (PEEK) has been reviewed in the paper. The tribological modification of PEEK composites which were reinforced by inorganic fillers, the fiber, polymer blends, plasma and mixed modification were introduced. Finally research progress of tribological modification of PEEK composites was forecasted.
\end{abstract}

Keywords: Polyetheretherketone, Modify, Composites, Tribological Property

\section{Introduction}

Poly ether ether ketone (PEEK) is a thermoplastic polymers that is developed successfully by British ICI company. Owing to its low friction coefficient and wear resistance, PEEK is widely applied in aerospace and automotive components since entering the market. With the development of high-tech, the requirement for performance of special engineering plastic from industry is becoming more and more higher. The composite strengthening and surface modification of PEEK has been the hot spot of research both in china and abroad because pure PEEK is hard to meet the needs of industry. Methods mainly include inorganic fillers, fiber reinforced, polymer blends and plasma modification, mixed modification which can improve its performance in self-lubricating, high temperature, high load and other harsh conditions and reduce material costs and expand applications $[1,2]$.

\section{The Characteristics of Peek}

PEEK resin is a new aromatic special engineering. The glass transition temperature (Tg) and melting point (Tm) temperatures of PEEK is $143^{\circ} \mathrm{C}$ and $334^{\circ} \mathrm{C}$ respectively. It can maintain good mechanical properties in a temperature range of $196^{\circ} \mathrm{C} \sim 260^{\circ} \mathrm{C}$ and work close to the temperature of $260^{\circ} \mathrm{C}$ for long-term. Its thermal stability is excellent, the degree of crystallinity is generally $20 \%$ to $30 \%$, can be up to $48 \%$, the density of PEEK is $1.265 \mathrm{~g} / \mathrm{cm}^{3}$ in the amorphous state [3]. PEEK chemical structural formula as shown in figure 1:

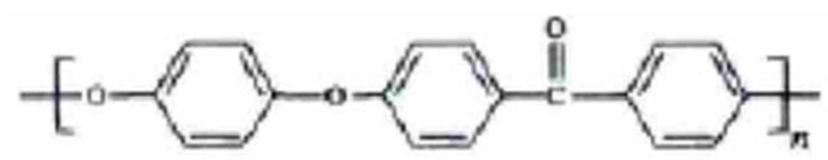

Figure 1. Polyether ether ketone chemical structural formula.

The macromolecular chains of PEEK contain a large number of aromatic rings, polar ketone group and an ether bond, so that it has excellent properties compared to other specialty engineering plastics, such as tribology performance, flame resistanc, workability excellent dimensional stability, fatigue resistance. In addition, PEEK has excellent corrosion resistance and good mechanical properties in high temperature under various organic and inorganic corrosion solution; PEEK with an excellent resistance to water, its products can keep constant performance under the temperature exceeds $250^{\circ} \mathrm{C}$ steam or high pressure water immersion with working for thousands of hours; PEEK itself is non-toxicity and approved by NSF (ational sanitation foundation: in the field of public health and safety authority) for using in contact with food. Which excellent properties 
make PEEK are widely used in the aerospace, automotive, medical, food, electronics, chemical, petrochemical, semiconductor and other fields $[4,6]$.

\section{The Progress of Tribology Modified}

\subsection{Inorganic Fillers Modification}

PEEK were reinforced by whiskers and nano-particles fill has the following excellent characteristics: reducing shrinkage and thermal expansion during molding products to improve the molding process, reducing friction and wear, promoting the formation of the transfer film; but its side effect is make the products become opaque and increase the density of products at times [7].

Whisker is a certain length to diameter ratio of metal oxide or salts new reinforced material with high strength, high modulus, heat resistance. Currently, whiskers is a modified reinforcing materials with the highest strength and optimal performance that mainly applied in he modification of metals, polymers, ceramics and other composite materials. PEEK modification by whiskers can improve the tribological properties, mechanical properties of composite materials and expand the application of PEEK composites $[8,10]$.

With unique chemical stability, thermal properties and mechanical properties, potassium titanate whisker (PTW) is widely used in reinforced composites. In recent years, mature preparation technology of potassium titanate make the product cost reduced, which make whisker reinforced composite material widely use in many areas, such as friction materials, high temperature insulation materials, insulation materials [11, 12]. With small size, large specific surface area, PTW affects the interface bonding strength between potassium titanate whiskers and polymer, which reduce the usability of composites. Therefore, the surface modification of PTW is very important to improve the usability of PEEK composites. Hua Man Yu [13] system studied six PTW and surface modification of six PTW modified tribological properties of PEEK composites. The results show that the friction coefficient and wear mass of composites decrease with the addition content of PTW. surface modification PTW better than PTW in modification effect, when the surface-modification PTW content of $15 \mathrm{wt} \%$, the friction coefficient and wear mass decreased by $60.50 \%$ and $59.21 \%$. Surface modification PTW can be fully distributed evenly in the PEEK matrix materials to help improve the hardness and strength, which can be very good to prevent deformation of the matrix material.

The load can affect the tribological performance of the composite under certain conditions. Xie G Y [14] researched results show that PEEK composites with high wear resistance and low coefficient of friction under low loads. Under the condition of load of $4 \mathrm{MPa}$, the best tribological behavior of the PTW/PEEK composites was obtained when the content of PTW is $5 \mathrm{wt} \%$. When the content of PTW further increased, the coefficient of friction and material temperature of composite increases at the same time. This is because PTW generate large number of grinding grain in the abrasive surface of composite, which make the friction and wear mechanism of abrasive wear turned to grain wear.

Lin Y X et al. [15] used hot pressing molding method to prepare $\mathrm{CaCO}_{3} / \mathrm{PEEK}$ composites and studied the friction and wear properties of the composites in MM-200 type wear tester. The results show, with the increase of $\mathrm{CaCO}_{3}$ content, the friction coefficient of PEEK composites is decreased, while the wear rate is firstly decreased and then increased. This is because $\mathrm{CaCO}_{3}$ whisker will gather even fall off as the content increasing, which make composite material occur abrasive wear and increases material wear rate. $\mathrm{CaCO}_{3}$ whisker improved the tribological properties of PEEK by reducing the adhesion, friction surfaces and the embedding, while contributing to the friction surface to form a uniform transfer film. Mechanism of whisker modified PEEK tribological performance is that with the addition of whisker the hardness of composite material increased, at the same time it plays a role of rigid skeleton in friction surface, which suppress the adhesion and thermoplastic deformation, helps to form uniform transfer membrane.

Nanoparticles become one of the main modified material for PEEK because of excellent mechanical properties, dimensional effect, surface activity [16]. Li M [17] studied the mechanism of nanoparticle $\mathrm{TiO}_{2}$ enhanced modified PEEK composites. The results in Fig. 2 show that: with the increment of $\mathrm{TiO}_{2}$ particles, the friction coefficient and wear mass of $\mathrm{TiO}_{2} /$ PEEK composites is firstly decreased and then increased. When the mass fraction of nanoparticles $\mathrm{TiO}_{2}$ is $5 \mathrm{wt} \%$, the tribological properties of $\mathrm{TiO}_{2} /$ PEEK composites is the best.

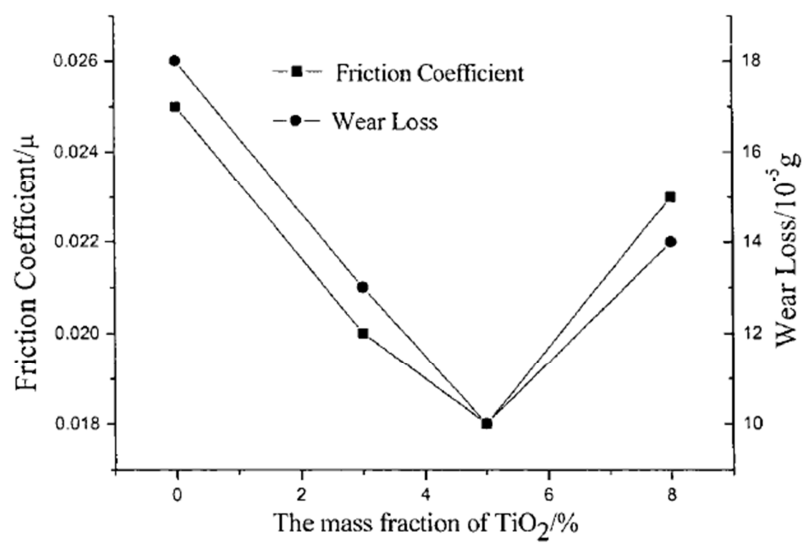

Figure 2. With change of $\mathrm{TiO}_{2}$ content and the friction coefficient and wear mass of $\mathrm{TiO}_{2} / \mathrm{PEEK}$ composites.

Reference [18, 20] shown that different types of nanoparticles filled PEEK have different tribological performance. When the filler content is $7.5 \mathrm{wt} \%$, the friction and wear behavior of PEEK composites filled with nanoparticles $\mathrm{SiO}_{2}, \mathrm{SiC}, \mathrm{Si}_{3} \mathrm{~N}_{4}, \mathrm{ZrO}_{2}$ as shown in table 1. Reference [20] shown that the same kind of particle with different size have different modification effects. When the content is $7.5 \mathrm{wt} \%$, tribology modifying effect of $10 \mathrm{~nm} \mathrm{ZrO}_{2} / \mathrm{PEEK}$ composites higher than $86 \mathrm{~nm} \mathrm{ZrO}_{2} / \mathrm{PEEK}$ composites. 
Table 1. The tribological properties of PEEK composites filled with $\mathrm{SiO}_{2}, \mathrm{SiC}$ $\mathrm{Si}_{3} \mathrm{~N}_{4}, \mathrm{ZrO}_{2}$

\begin{tabular}{lllll}
\hline Character & PEEK & $\mathbf{S i C}$ & $\mathbf{S i O}_{2}$ & $\mathbf{S i}_{3} \mathbf{N}_{4}$ \\
\hline friction coefficient $(\mathrm{u})$ & 0.38 & 0.22 & 0.23 & 0.24 \\
wear rate $\left(10^{6} /\left[\mathrm{mm}^{3} \cdot(\mathrm{N} \cdot \mathrm{m})^{-1}\right]\right)$ & 7.82 & 3.95 & 3.2 & 2.2 \\
\hline
\end{tabular}

Note: The studied useMM-200 type wear tester, mating plate is a 45 steel ring with diameter of $40 \mathrm{~mm}$ and surface hardness of HRC 48.5 .

Tian $\mathrm{A} G$ et al. [21] results show that nano- $\mathrm{Al}_{2} \mathrm{O}_{3}$ and nano- $\mathrm{SiO}_{2}$ can improve the tribological properties of composite materials, but the wear rate of nano- $\mathrm{A}_{2} \mathrm{O}_{3}$ filled composites lower than nano- $\mathrm{SiO}_{2}$. The best tribological behavior of the $\mathrm{A}_{2} \mathrm{O}_{3} /$ PEEK composites was obtained when the content of $\mathrm{Al}_{2} \mathrm{O}_{3}$ is $5 \mathrm{wt} \%$. Nanoparticles can improve the tribological performance of PEEK for the following three aspects: Firstly, the nanoparticles can be formed a thin and uniform transfer film on the surface of the friction layer; Secondly, nano-particles with excellent mechanical properties can play a role in load bearing in the course of friction; Thirdly, nanoparticles will not happen abrasive wear and mainly fatigue wear in friction surface.

\subsection{The Fiber Reinforced}

Fiber has some characteristics such as good insulation, heat resistance, good corrosion resistance, high mechanical strength. Fiber reinforced polymer material has the characteristics of easying to processing molding that the glass fiber and carbon fiber is often used as composite reinforced material.

There is a difference of the tribological performance of composite materials under different friction medium. Li E Z et al. [22] studied the friction and wear behavior of glass fiber (GF) reinforced PEEK composites under the condition of dry friction and water lubrication. The results show: with the increase of the load, PEEK and GF/PEEK conditions friction coefficient and wear rate increased gradually and finally tends to stable. Compared to pure PEEK composites, glass fiber can reduce the GF/PEEK conditions friction coefficient and wear rate. Under water lubrication, PEEK and GF/PEEK conditions friction coefficient and wear rate is lower than under the dry friction.

Carbon fiber ( $\mathrm{CF}$ ) with high strength, thermal conductivity, self-lubricating, anti-corrosion and wear, so it is the most popular filler for reinforcing polymers. However, its chemical inertness and surface smoothness make the strength of fiber-matrix interface become relatively weak and thus affects the tribological properties of composites. Mohit Sharma [23] studied the tribological performance of surface modification carbon fiber reinforced PEEK composites. The results show that the interfacial strength between plasma treated carbon fiber and PEEK becomes strong. Compared with the pure PEEK and unmodified CF/PEEK, the wear rate and friction coefficient of surface modification $\mathrm{CF} / \mathrm{PEEK}$ composites is relatively lower and its wear resistances increased by $26 \%$.

Effects of preparation process on wear resistance of carbon fiber reinforced PEEK composites have been studied in the article [24]. Composite was manufactured by twin-screw extruder with rmelting temperature of $340^{\circ} \mathrm{C}, 360^{\circ} \mathrm{C}$ and $380^{\circ} \mathrm{C}$ respectively and tesed. The results show that PEEK composite material was prepared under the melting temperature of $360^{\circ} \mathrm{C}$ have optimal physical properties. The reason is that a melting temperature of $360^{\circ} \mathrm{C}$ close to the melting point of PEEK make two kinds of materials mix evenly. In addition, the author used coupling agent (titanate and silane treated by ethanol activation) treated the surface of carbon fibers and prepared CF/PEEK composites. It can be found surface-treated CF/PEEK composite was obviously lower than $\mathrm{CF} / \mathrm{PEEK}$ composite on the wear of surface. This shows that the distribution and surface modification of carbon fiber play an important role in the tribological properties of PEEK composites.

The study found the content of carbon fiber, length and oxidized surfaces have a great influence on the tribological properties of CF/PEEK composite. Wu Xinxin [25] research results show that the effect from large to small in turn is add quantity, surface oxidation treatment, the fiber length. With the increment of $\mathrm{CF}$, the friction coefficient and wear mass of $\mathrm{CF} / \mathrm{PEEK}$ composites is firstly decreased and then increased. When the mass content of $\mathrm{CF}$ is $15 \mathrm{wt} \%$, the tribological properties of CF/PEEK composites is the best and about $1 / 8$ of pure PEEK. For the length of carbon fibers, friction and wear properties of long carbon fiber filled PEEK composites superior to short carbon fiber; For surface oxidation effects, surface oxidation treatment can improve the CF/PEEK tribological properties of the composites. Li Hao [26] studied also showed that tribological properties of the length of $3 \sim 6$ $\mathrm{mm}$ carbon fiber reinforced PEEK composites superior to carbon fiber length of $1 \sim 3 \mathrm{~mm}$. Therefore, the content of carbon fiber, surface modification methods and optimize the design of length are a substantial contribution for improving the tribological properties of composite.

\subsection{Polymer Blends}

Generally, polymer blends was made two or more different molecular structure of polymer by blending, which including mechanical blending, solution blending or latex blending. Since PEEK resin can be prepared composite material with unique properties by simple blending, and therefore PEEK blending very popular.

Polytetrafluoroethylene (PFTE), having high wear rate, high temperature resistant and low friction coefficient, is widely used as a good solid lubricant. It has been reported that adding PTFE into composite material can reduce the friction coefficient [16, 27, 29]. Figure 3 shows with the increase of mass fraction of PTFE, friction coefficient of the composites are obviously declined. In ensuring composites have better tribological properties, PTFE content should be 0.10 to 0.20 . Figure 4 shows the relationship between the temperature and friction coefficient of pure PTFE, PEEK pure and PEEK / PTFE composite. Seen from figure 4 , the friction coefficient of the composite is lower than both the friction coefficient of each pure component with in the scope of the $50 \sim 200^{\circ} \mathrm{C}$. 


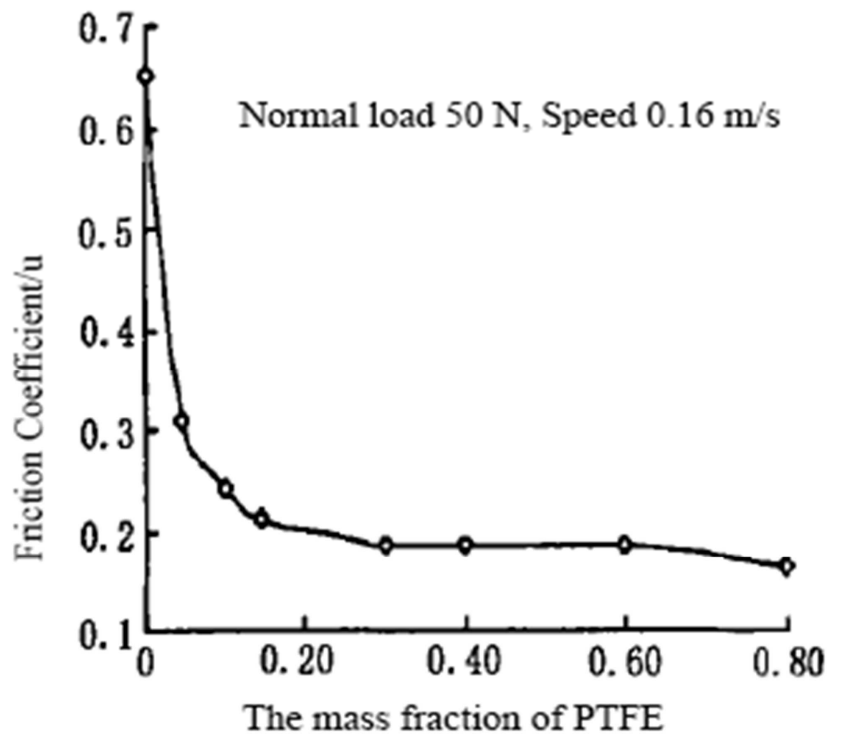

Figure 3. PEEK/PTFE composites friction coefficient with the mass fraction of relations.

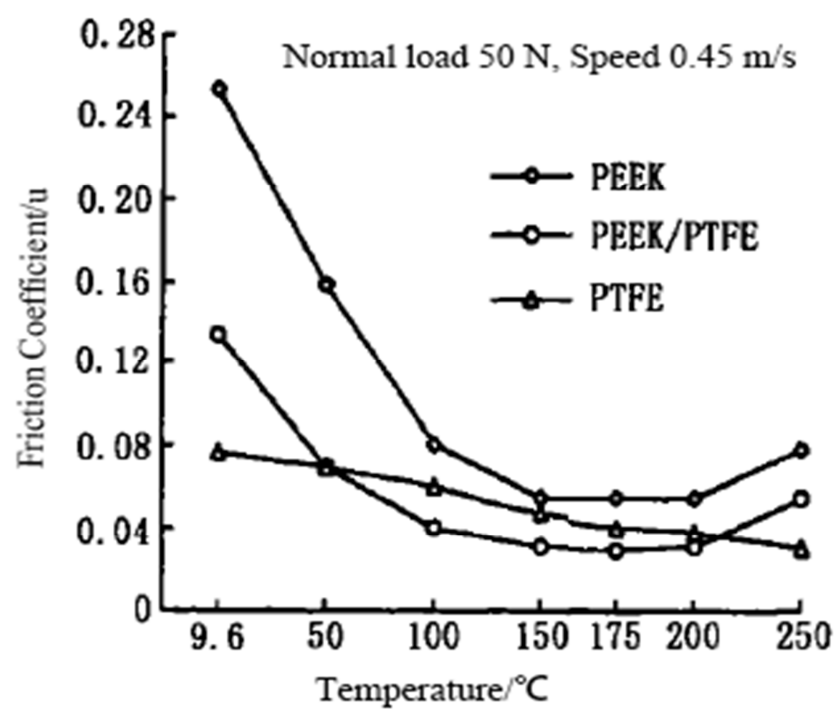

Figure 4. The relationship between friction coefficient and temperature.

The tribological performance of graphite and PTFE reinforced PEEK composites was studied by Hong-xia yan and others [30]. Experimental results show that two materials can make the friction coefficient of PEEK composites decrease. Especially, the friction coefficient of PTFE reinforced PEEK composites are smaller, only 0.18. Lin You xi et al [31] used PTFE filled PEEK to prepare self-lubricating composites by molding method and compared the composite tribological performance with pure PEEK. The results showed that PTFE can improve the tribological performance of PEEK composites. Compared with pure PEEK, the friction coefficient of composite materials reduce $50 \%$ and wear resistance increase 26 times. PTFE can reduce the friction coefficient of PEEK composites because PTFE can generate lubricating film in the dual plane.

Chen J B [32, 33] used twin screw extruder prepare different PEEK/Polyetherimide (PEI)/Polyethersulfone (PES) contains ternary plastic alloy and test tribology performance of pure PEEK, PEI, PES and ternary plastic alloy under dry conditions. The test results show that: due to high wear of PEI and PES, ternary plastic alloy is 7 9 times the wear rate of pure PEEK; However, plastic alloy can produce a transfer film without appearing in pure PEI and PES. The transfer film is can reduce friction and wear of plastic alloys; PEI can completely compatible with PEEK because the structure of PEI similar to PEEK; The compatibility of PES and PEEK is poor, but PES can improve the crystallization properties of PEEK; when the three polymers blended, PEI can improve the compatibility of PES and PEEK, so that ternary plastic alloy having a glass transition temperature.

Considering the PEEK glass transition temperature is too low so limit the usability under high temperature conditions. Zhang Zhi Yi [34] used engineering plastics - phenolphthalein polyethersulfone (PES-C) with the glass transition temperature of $265^{\circ} \mathrm{C}$ to modified PEEK. The study found that the tribological properties of PEEK composites related to its phase structure and loads, however, phase structure is related to the content. When PEEK is the continuous phase, PEEK of low friction coefficient bear the primary friction and make the friction coefficient of composite materials low; however, when the PES-C is the continuous phase, poly ether sulfone bear the primary friction and result in a higher friction coefficient of composite materials. With the increase of load, the friction coefficient of PEEK composites increases is firstly increased and then decreased. This is because the load increased to a certain degree, friction heat make viscosity and composites friction coefficient increase.

\subsection{Plasma Modification}

In some cases, the application of polymer materials depends on its surface properties in certain industries [35]. PEEK itself biological inertia and high water resistance limit its application in many fields. Surface modification methods including physical method and chemical method. Surface modification mechanism that changing the surface structure of PEEK general, hydrophilic and water resistance to improve the bonding strength of the composites, mechanical properties and tribological properties [36].

The surface of PEEK by plasma treatment is more smooth and hardness, the degree of improvement is related to inject ion species and ion implantation way [37]. Studies shown that polymer modified by high-energy ion and dual ion implantation present wear layer and a strong cross-linking [38, 39]. The hardness of PEEK modified by dual ion up to $22 \mathrm{GPa}$. PEEK present stick-slip behavior in micro friction, this is because the plasma-treated surface form a three-dimensional cross-linked structure. Du P [40] injected respectively $\mathrm{Cu}$ and $\mathrm{Ag}$ ions into the PEEK surface. It is shown that with the content increase of ion, color of PEEK surface changed from offwhite to black. ATR-FTIR spectroscopy found that graphite phase was foud on PEKK surface, meanwhile the PEEK surface hardness, mechanical properties and Young's modulus increased significantly. 


\subsection{Mixed Modification}

A single material can only improve the performance of a particular aspect or aspects of PEEK, even sometimes degrade the performance of certain aspects. Mixed-reinforced composite material is made up of two or more reinforcement material in a matrix material. Using a variety of different materials modified PEEK can improve its comprehensive performance. However, relatively few studies have been done to studied the tribological of PEEK reinforced by mixed filler, thus it has attracted more and more attention in recent years. The study shows that the friction and wear properties of PEEK can be improve by filling a variety of fillers. Tribological properties of PEEK reinforced by $\mathrm{TiO}_{2}$ and PTFE was studied in the literature $[41,42]$. The results showed that the wear rate of PTFE/PEEK composite materials that was filled by nano $\mathrm{TiO}_{2}$ is only $50 \%$ of PTFE/PEEK composite materials, and the abrasive dust is less obvious. M. Y. H [13] found that when we added the PTW/PEEK composite materials into the PTFE, the friction coefficient of composites under each whisker content decreased and it's frication coefficient falled by $62.5 \%$ relative to PEEK matrix. So it shows that PTFE has synergetic anti-friction effect with PTW.

We can use the excellent mechanical properties of inorganic particles and good lubrication performance of polymer, and through both synergy to improve the tribological properties of PEEK composites. The mixed modification mechanism lies in two aspects: One is that inorganic particles could support load and reduce the size of polymers to improve material's mechanics performance. The other is that we can improve the tribological properties of polymer by promoting and improving the transfer film and adhesion strength of high polymer.

Short carbon fiber and potassium titanate whisker have good enhancement for polymer matrix, but also have their own limitations. $\mathrm{M} \mathrm{N}$ [43] prepared PTW/CF/PEEK composites by injection molding. Studies shown that PEEK/PTW composites appeared fatigue wear and abrasive wear. However, CF/PEEK composites appeared mainly abrasive wear and CF began to come off. Due to the synergy between the fibers and the whiskers, PTW/CF/PEEK composites have more excellent than CF / PEEK and PTW / PEEK.

\section{Conclusion}

Adopting inorganic filler filling modification, filling fiber reinforcement, polymer blending, plasma modification mixed modification method to improve the tribological properties of PEEK composites, which made significant contributions to expand the application field of PEEK. Although the PEEK tribological modification research has made great progress, there a big gap with the current demand. At present, research on the modification of PEEK mainly concentrated in a single material modification. Relatively few studies have been done to studied the wear mechanism of peek. Therefore, the wear mechanism of PEEK composites under a variety of modified materials research synergy is an important direction for future research.

\section{Acknowledgement}

The authors would like to thank the National Natural Science Foundation of P.R. China for thefinancial support (ID: 41108336).

\section{References}

[1] X. M. Wang, G. L. Qi, J. T. Cai, Y. L. Zhang. Progress modified PEEK [J] Engineering Plastics Application, 2009, 37(2): 80-83.

[2] Y. W. Li. Advances in poly (ether ether ketone)-based composites [J]. New Chemical Materials, 2009, 37(3), 37-39.

[3] Y. F. LI, X. M. WU. Application and development prospect of special engineering plastics PEEK [J]. Chemical Propellants \& Polymeric Materials, 2005, 3(3): 7-11.

[4] Z. C. Ni. Development and application of domestic and foreign PEEK [J]. World Plastics, 2013, 31(10): 32-36.

[5] Z. S. Tan, J. Li. A Study on performance of PEEK materials and use of themin food packaging and beverage machinery industries [J]. Beverage Industry, 2014, 17, 39-42.

[6] G. T. Fu, H. J. Liu, et al. PEEK properties and applications [J]. engineering plastics application, 2006, 34(10): 69-71.

[7] E. Z. LI, W. L. Guo, et al. Progress of tribological modification and application of PEEK [J]. Journal of Materials Engineering, 2013(1): 91-96.

[8] M. Yang, Luo shi kai, et al. Application of whiskers in polymer composites [J]. Materials Review, 2014, 28(3): 51-55.

[9] J. P. Peng, W. S. Zhou, ei al. Whiskers mechanism and its application in composites [J]. Journal of Saltlake Research, 2005, 13(2): 1-6.

[10] F. W. Cheng, J. Qi, Z. J. Zhang. research progress on Wear-Resisting modification of PEEK [J]. Engineering Plastics Application, 2014, 42(1): 126-129.

[11] Y. Z. Meng, Y. Shen, et al. Modified potassium titanate whisker and its application in composites [J]. ShanDong Ceramics. 2015: 15-18.

[12] X. Feng, J. Z. Lv, et al. The application of potassium titanate whisker in the composite materials [J]. Acta Materiae Compositae Sinica, 1999, 16(4): 1-7.

[13] Y. H. Man. Studies on mechanical/tribological properties of potassium hexatitanate whisker/PEEK composites and the interfacial bonding mechanis [D]. Changsha. Powder Metallurgy Institute of Central South University, 2014. 5.

[14] G. Y. Xie, G. X. Sui, R. Yang. Yang R. The effect of applied load on tribological behaviors of potassium titanate whiskers reinforced PEEK composites under water lubricated condition [J]. Tribology letters, 2010, 38(1): 87-96.

[15] Y. X. Lin, et al. The effects of potassium titanate whiskers filled PEEK on the tribological properties [J]. Tribology, 2006, 26(5): 448-451.

[16] X. D. Peng, Y. Lei, H. Y. Ma. Progress in tribology PEEK matrix composites [J]. Journal of the University of Petroleum, 2002, 26(1): 119-122. 
[17] M. Li. Study of the Performance of PEEK composite using on Non-lubricated CNG compressor [D]. Shanghai. School of Mechanical Engineering, East China University of Science and Technology, 2012, 1, 11.

[18] Q. H. Wang, et al. The research on friction and wear mechanism of nanometer $\mathrm{SiC}, \mathrm{SiO}_{2}$ and $\mathrm{Si}_{3} \mathrm{~N}_{4}$ filling polyether ether ketone [J]. Functional materials, 1998.10: 964-966.

[19] Q. H. Wang, et al. Sem investigations of worn surfaces and transfer files of PEEK filled with nanometer $\mathrm{ZrO}_{2}$ [J]. CJMR, 1999. 13(1): 107-109.

[20] Q. H. Wang, et al. The effect of nanometer SiC filler on the tribological behavior of PEEK [J]. Wear, 1997, 209(1): 316-321.

[21] A. G. Tian. Nanometer $\mathrm{Al}_{2} \mathrm{O}_{3}$ reinforced PEEK composites and their properties [D]. Mechanical Engineering Research Institute, 2002.

[22] E. Z. Li, X. H. Bin, et al. Tribological property of PEEK composites reinforced with glass fiber under water lubricated $[\mathrm{J}]$. Materials engineering, 2014, 3(5): 77-82.

[23] S. Mohit, B. Jayashre, et al. Strengthening of CF/PEEK interface to improve the tribological performance in low amplitude oscillating wear mode [J]. Wear, 2013, 301: 735-739.

[24] L Wu. The preparation of carbon fiber reinforced PEEKcomposites technology and wear resistance and electric conductivity study [J]. Guangdong chemical, 2014. 41(15): 74-75.

[25] X. X. Wu. Tribological properties of carbon fiber reinforeed PEEK [D]. Nan Jing. Nanjing University of Science and Technology, 2012. 3. 27.

[26] LI hao. Preparation and characterization of short carbon fiber reinforced composites [D]. Tian Jin: Tianjin University, 2006.

[27] B. JBRISCOE, et al. The friction and wear of PTFE-PEEK composites: an initial appraisal of the optimum composition [J]. Wear. 1986, 108: 357-374.

[28] B. JBRISCOE, B. J, et al. Boundary lubrication of polymers in model fluids [J]. Tribology Inter, 1984, 17(1): 129-137.

[29] B. JBRISCOE, B. J. Friction and Wear of Polymer Composites [M]. Friedrich K ED, Elesvier, Oxford, 1986.

[30] H. X. Yan, R. C. Ning, Y. Huang. The performance of PEEK composites research [J]. China Plastics Industry, 2002, 30(4): 44-45.
[31] Y. X. Lin, C. H. Gao, Y. Li. Eeffet of $\mathrm{CaCO}_{3}$ whisker and PTFE on dry frietion behavior of PEEK [J]. CJMR, 2007, 6 (2): 643-647.

[32] J. B. Chen, Q. Guo, et al. Research on friction and wear behaviors of PEEK/PEI/PES Plastics alloys under sliding contact condition [J]. Procedia Engineering, 2012, 36: 285-291.

[33] J. B. Chen. Research on structures and properties of ternary high performance plastics alloys PEEK/PEI/PES [D]. Shang hai: Shang hai University, 2013.

[34] Z. Y. Zhang, H. M. Zeng. Study on the friction and wear properties of PEEK/PES-C blends [J]. Plastics, 1993, 22(2): 31-34.

[35] B. Yameen, M. Alvarez, O. Azzaroni, et al. Tailoring of PEEK Surface properties via surface-initiated atom transfer radical polymerization [J]. Langmuir, 2009, 25(11): 6214-6220.

[36] R. C. Chen, H. Sun. G, Z. Xu. Surface Modification and characterization of PEEK [J]. China Plastics, 2011, 25(5): 17-23.

[37] E. H. Lee, M. B. Lew, P. J. Blau, et al. Improved surface properties of polymer materials by multiple ion beam treatment [J]. JMater Res, 1991, 6(3): 610-628.

[38] E. H. Lee, G. R. Rao, L. K. Mansur. Improved hardness and wear properties of bion implanted polycarbonate $[\mathrm{J}]$. JMater Res, 1992, 7(7): 1900-1911.

[39] Rao G R, Lee E H. Effects of sequential He+ and Ar+ implantation on surface properties of polymers [J]. JMater Res, 1996, 11(10): 2661-2 667

[40] P. Du, X. M. Yang, M. Li. Surface modification of polyether ether ketone thin films through ion implantation [J]. Journal of Materials Science \& Engineering, 2010(4): 481-485.

[41] $\mathrm{L} \mathrm{W} \mathrm{Mu}$, et al. Effects of nano-and micro-TiO2 on PTFE/PEEK composites tribological performance $[\mathrm{J}]$. Journal of nanjing technology universit. 2014, 36(6): 31-36.

[42] X D Peng, H Y Ma, Q F Zeng, Y Lei. Tribological properties of polyetheretherketone composite materials filled by inorganic nanoparticles and PTFE [J].Tribology, 2004, 24(3): 240-243.

[43] N Ma, G X Sui. The tribological mechanism of short carbon fibers and potassium titanate whiskers reinforced polyetherrtherkrtone composites in dry sliding [J]. Acta Materiae Compositae Sinica, 2013, 30(12): 49-54. 